\title{
ESTRUTURAS DE GOVERNANÇA NA CADEIA PRODUTIVA VITIVINÍCOLA DO MEIO-OESTE DE SANTA CATARINA: UM ESTUDO A PARTIR DOS SEGMENTOS PRODUTOR E BENEFICIADOR
}

\author{
Structures of Governance in Wine Production Chain in the Midwest of Santa Catarina: \\ A Study from Segment Producer and Processor
}

\begin{abstract}
RESUMO
O objetivo deste estudo é analisar as relações entre produtor e beneficiador da cadeia produtiva vitivinícola do Meio-Oeste de Santa Catarina, compreendendo as estruturas de governança que amparam tais relações. O suporte teórico baseia-se na Teoria dos Custos de Transação (TCT) e Teoria dos Custos de Mensuração (TCM). Destas abordagens foram criadas categorias de análise que serviram de base para a elaboração das questões contidas nas entrevistas feitas com produtores e vinícolas da região. No segmento produtor, observou-se que as relações são baseadas na confiança, dada à inexistência de contratos que amparem as transações. Constatou-se que os produtores de uva mantêm relações com as vinícolas quando estas necessitam da fruta para complementar a produção existente ou quando não dispõem de produção própria. Já no segmento beneficiador, a estrutura verticalmente integrada é adotada quando há presença de ativos específicos, os custos de governar a transação internamente são menores do que externamente, e mediante a dificuldade de mensuração dos atributos dos ativos. As formas híbridas também são adotadas, no segmento beneficiador, quando não há dificuldade de mensuração dos atributos dos ativos e os custos de transação externos são menores do que os internos. Conclui-se, portanto, que as estruturas de governança adotadas pelos segmentos na região em estudo são integração vertical e formas híbridas.
\end{abstract}

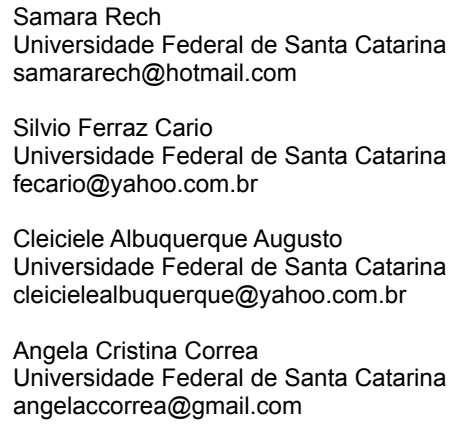

\begin{abstract}
The aim of this study is to analyze the relationships between producers and beneficiaries of the wine production chain in the Midwest of Santa Catarina, understanding the governance structures that compare these relationships. Theoretical support is based on the Theory of Transaction Costs (TCT) and the Theory of Measurement Costs (TCM). From these approaches, categories of analysis were used that served as a basis for the elaboration of questions contained in the interviews made with producers and wineries in the region. No producing segments, allowed if the relationships are identified in the trust, given the absence of contracts that apply as records. It appears that grape producers maintain relations with wineries when these fruits are used to complement existing production or when they do not have their own production. There is no longer a benefited segment, a vertically integrated structure is adopted when assets are present, governance costs and internal transactions are lower than externally, and using the difficulty of measuring asset assets. As hybrid forms are also adopted, without a beneficiary segment, when there is no difficulty in measuring the attributes of the assets and external transaction costs are lower than the internal ones. It is concluded, therefore, that the governance structures adopted by the segments in the region under study are vertical integration and hybrid forms.
\end{abstract}

Palavras-chave: Vitivinicultura. Custos de Transação. Custos de Mensuração. Meio-Oeste catarinense.

Keywords: Viticulture. Transaction Costs. Measurement Costs. Santa Catarina Midwest.

\section{INTRODUÇÃO}

O objeto central da análise deste trabalho são as estruturas de governança, responsáveis pela coordenação das atividades organizacionais, partindo do enfoque da Nova Economia Institucional (NEI). Nessa proposta, duas abordagens do nível micro da NEI são utilizadas para 
justificar a melhor forma de coordenação das atividades, a Teoria dos Custos de Transação (TCT) e a Teoria dos Custos de Mensuração (TCM). Dessa forma, elementos transacionais apontados por Williamson $(1985,1996,2002)$, e de mensuração destacados por Barzel (2002, 2004, 2005), podem influenciar nas decisões de produzir internamente, integralizando verticalmente, ou adquirir externamente, por meio das formas híbridas ou do mercado.

As duas vertentes teóricas serão consideradas ao analisar a cadeia produtiva vitivinícola, presente no Meio-Oeste de Santa Catarina, sob a perspectiva de dois elos que a compõe: produtores e beneficiadores. As vinícolas, responsáveis pelo processamento da uva, registraram incremento na produção nos últimos anos, exigindo mudança na forma de governar suas atividades. Observações preliminares apontam que a maioria das vinícolas da região não são autossuficientes na produção de uva, bem como algumas necessitam de vinho de outras vinícolas para complementar a produção própria.

Neste contexto, há vinícolas que atuam de maneira independente, realizando as atividades de produção de uva, fabricação e comercialização do vinho. Não obstante, há também vinícolas que adquirem a totalidade ou parcela da uva de terceiros e as que complementam sua produção com vinhos de outras vinícolas. A insuficiência produtiva, notadamente no que se refere às uvas, exige que a vinícola transacione com produtores tanto locais, quanto de outras regiões.

De outra perspectiva, a incapacidade de suprir a necessidade da fruta por parte da vinícola dá aos produtores uma garantia de venda da produção. Isso faz com que estes destinem sua produção quase que exclusivamente para as cantinas da região, o que possibilita uma frequência maior nas relações entre produtores e beneficiadores. Além disso, o aumento nas transações tende a fidelizar e estimular a confiança entre as partes.

Considerando que os segmentos são interdependentes, abre-se a possibilidade de realizar um estudo que possibilite compreender como essas relações ocorrem naquela região. Frente a isso, as transações entre estes elos exigem capacidade de adequação e coordenação das atividades. Por esse motivo, as estruturas de governança adotadas pelas vinícolas buscam minimizar os custos das negociações e garantir os direitos dos envolvidos. Sob a ótica da TCT são considerados os atributos das transações e os pressupostos comportamentais dos indivíduos, que quando alinhados à estrutura de governança, tendem a reduzir os custos das transações. Do ponto de vista da TCM, elementos como o nível de informação e de padronização dos produtos, assim como a os direitos de propriedade são considerados.

A importância que os dois elos têm para essa cadeia é significativa, dado que juntos são responsáveis pela transformação da uva em vinho. A região foi selecionada para este estudo pela tradição que possui na produção da fruta e fabricação da bebida, resultado do pioneirismo na atuação dos dois segmentos em nível estadual, além do potencial produtivo e econômico que conquistou. Ademais, a região é destaque pelo volume produzido e pela importância que a produção vitivinícola tem para os municípios que a compõe.

Frente ao exposto, propõe-se analisar as relações entre os elos produtor e beneficiador, no Meio-Oeste catarinense utilizando as estruturas de governança para justificar tais relações. Apesar da relevância, a cadeia vitivinícola na região selecionada carece de um estudo aprofundado que destaque como os dois segmentos se relacionam e transformam a matéria prima no produto final. Além de compreender como os dois segmentos coordenam suas transações, através das formas de governança. Diante disso, propõe-se responder como se configuram as relações entre produtor e beneficiador da cadeia produtiva vitivinícola do Meio-Oeste de Santa Catarina, baseada no referencial teórico proposto.

Para atingir tal objetivo, o presente artigo apresenta, além desta introdução, uma segunda seção que apresenta a fundamentação teórica, com foco na TCT e na TCM; uma terceira seção que apresenta os procedimentos metodológicos utilizados; uma quarta seção em que os resultados são discutidos e, por fim, a conclusão é feita e as referências são disponibilizadas.

\section{FUNDAMENTAÇÃO TEÓRICA}

\subsection{Teoria dos Custos de Transação (TCT)}

A Teoria dos Custos de Transação (TCT) propõe um panorama teórico que permite analisar os problemas associados ao funcionamento interno das organizações, sendo substitutas do mercado na função de coordenar a produção. De um modo geral, "a TCT dedica-se a compreender as transações econômicas e explora as vantagens contingentes dos arranjos organizacionais, buscando responder, por exemplo, porque algumas transações são internas e outras externas às organizações" (SANTOS; FERRAZ; FALQUETO; VERGA, 2017, p. 7).

Ronald Coase foi um dos precursores desta teoria, destacando aspectos como a natureza e os limites da 
organização. Coase (1937) apresenta a hipótese de que existem custos para que um produtor recorra ao mercado. Além dos custos relacionados à produção, existem custos de se utilizar o mercado.

Quanto ao crescimento das organizações, Coase (1937, p.7, tradução nossa), propõe que "uma empresa tenderá a se expandir até os custos da organização de uma operação adicional dentro da empresa tornar-se igual aos custos de realização da mesma transação por meio de uma troca no mercado aberto ou as despesas de organização em outra empresa". A partir desse momento, na concepção do autor, a firma apresenta retornos decrescentes, o ideal seria que desse ponto em diante a firma passasse a adquirir ativos externamente.

Zylbersztajn (2005) apresenta a possibilidade de analisar as organizações como arranjos institucionais que orientam as transações por meio de contratos formais, amparados pela lei ou por acordos informais, amparado por salvaguardas reputacionais. Além desses, outros mecanismos sociais surgiram a partir da perspectiva da firma como sendo formada por um conjunto de contratos.

Williamson (2002) aponta que a escolha da estrutura de governança adequada à organização é resultado da opção make or buy, isto é, a organização opta por produzir seus produtos dentro dos limites da firma, adquirindo produtos de outras empresas por meio de contratos, ou ainda, comprando no mercado livre. Neste sentido, Williamson (2002, p.16, tradução nossa), destaca que "transações simples são gerenciados pela governança do mercado, [...] enquanto que as operações complexas são incorporadas nas estruturas de governança em que a cooperação bilateral é facilitada".

A integração vertical corresponde a uma estrutura em que as atividades são desenvolvidas pela firma. Argyres e Zenger (2012) propõe que as atividades devem ser internalizadas quando o custo de governar as mesmas por meio do mercado excede o custo de gerencia-la hierarquicamente na empresa.

A estrutura via mercado corresponde à compra de produtos no mercado livre, ou seja, a empresa deixa de produzir dentro da firma para adquirir externamente. Segundo Williamson (1985), as transações via mercado são também conhecidas como transação de curta distância, caracterizadas pelo simples pagamento pela entrega ou serviço de troca realizado entre compradores e vendedores.

Para Ménard (2004, 2018), as formas híbridas, são classificadas em um patamar entre as estruturas de mercado e a hierarquia, combinando elementos de ambas. Para o autor, os híbridos podem ser definidos com mais rigor como a organização de transações entre entidades legalmente autônomas que mantêm os direitos estratégicos de propriedade separados, mas compartilham direitos significativos de decisão, porque é a melhor maneira de criar valor agregado: somente o uso conjunto dos ativos relevantes pode gerar um excedente (MÉNARD, 2018). Algumas formas híbridas documentadas na literatura são: subcontratadas, redes de empresas, franquias, alianças, parcerias e cooperativas.

Neste sentido, quando as empresas se afastam dos mercados e se direcionam para uma estrutura mais hierarquizada os incentivos são reduzidos, além da burocracia e dos custos serem menores. Contudo, integralizando verticalmente ganha-se em autoridade, permitindo maior controle das atividades e facilitando possíveis resolução de disputas (WILLIAMSON, 1985, 1996; CROOK et al, 2013; NEVES; HAMACHER; SCAVARDA, 2014).

A existência de estruturas de governança é explicada pelo fato de haver diferenças entre as transações. Essas diferenças são ocasionadas, segundo Williamson (1985, 1996), por fatores como frequência, incerteza e especificidade dos ativos. Para Williamson (1996) este último é o fator mais importante na escolha da estrutura de governança a ser adotada. O autor define ativos específicos como sendo a perda do valor dos ativos envolvidos em uma transação quando o uso desses ativos não é destinado à sua finalidade. Diante da especificidade dos ativos, a integração vertical é a forma de governança mais eficiente, reduzindo a chance de comportamento oportunista e a apropriação de quase renda (WILLIAMSON, 1985; MÉNARD; SHIRLEI, 2014).

Por outro lado, Caleman (2017, p. 465, tradução nossa) destaca que "apesar da convergência esperada para um modelo considerado mais eficiente, na perspectiva da Economia dos Custos de Transação, o que se vê é a coexistência de arranjos no mesmo contexto institucional. Segundo a autora, observa-se que alguns sistemas agroindustriais demonstram maior ou menor tolerância a modelos organizacionais rígidos.

Os pressupostos comportamentais em que se apoia a TCT, segundo Williamson (1985) são a racionalidade limitada e o oportunismo dos agentes, apresentados como influenciadores dos custos de transação. Para o autor, ambos os pressupostos estão presentes no ambiente econômico e resultam da limitação cognitiva e do comportamento oportunista dos indivíduos.

\subsection{Teoria dos Custos de Mensuração (TCM)}

Os custos de mensuração são, na concepção de North (1998, p.8-9), os “custos de quantificação dos 
atributos de valor dos bens e serviços ou do desempenho dos agentes", sendo provenientes "dos diversos atributos de valor do bem ou serviço ou, no caso do desempenho de um agente, das inúmeras atividades isoladas que constituem esse desempenho". O autor destaca que o custo de quantificar os atributos de valor dos ativos, assim como do desempenho dos agentes, é a chave dos custos de transação.

Para Barzel (2005), a TCM tem como unidade de análise as dimensões mensuráveis dos produtos, sendo estas garantidas pelos direitos de propriedade e amparadas pela troca de informações. Partindo das dimensões que compreendem a TCM, North (1998), propõe que mensurar consiste em considerar não só as dimensões físicas dos atributos do objeto transacionado, tais como tamanho, peso, cor, mas também os direitos de propriedade envolvidos na troca.

Em relação aos direitos de propriedade, Ménard (2018) os identifica como a capacidade de controlar a transferência de direitos necessários para organizar as transações e ser o reclamante residual no resultado. Em outros termos, o requerente residual determina o que fazer com os recursos disponíveis e as condições sob as quais os direitos sobre esses recursos podem ser transferidos. Nesse sentido, se destacam os direitos de propriedade legais e econômicos (BARZEL, 2002).

Segundo Barzel (2002) e Zylbersztajn (2005), quando os atributos possuem facilidade de mensuração estão associados a direitos legais que podem ser contratados, já que são garantidos pelo Estado. Convergindo para o exposto por Barzel (2004, p.51, tradução nossa), de que "os direitos legais são os direitos que o Estado reconhece como os de um indivíduo em particular ou de um conjunto de indivíduos". Por outro lado, existem os direitos econômicos que, segundo Barzel (2002, p.6, tradução nossa), "refletem a habilidade dos indivíduos para consumir ou trocar commodities", ou seja, são os direitos garantidos privadamente, por meio de mecanismos de reputação.

Os direitos de propriedade são influenciados pelas informações que os agentes detêm sobre os atributos das mercadorias que estão sendo transacionadas. Segundo Barzel (2005), diante da dificuldade em se conseguir informações precisas e sem custos erros são inevitáveis, e por isso, as disputas existem. Pelo fato de que a informação é incompleta, os direitos individuais não são claramente delineados. Nesse sentido, Caleman (2017) indica a necessidade de políticas públicas e privadas destinadas a produzir informação e reduzir custos de mensuração, como acesso a novas tecnologias e / ou programas que facilitam a mensuração de atributos. Para a autora isso poderia reduzir os custos de transação e fornecer maior eficiência aos arranjos identificados.

Em relação às estruturas de governança, na visão de Barzel (2005), a internalização das atividades, ou integração vertical, é favorável quando o custo de mensurar os itens é alto. As mercadorias com baixo custo de mensuração, por sua vez, têm possibilidade de serem compradas e transacionadas no mercado. Ou seja, se puder ser mensurado a baixo custo, a mercadoria pode ser adquirida fora da firma, o que prevê garantia da justiça no caso de quebra de contrato, sendo amparadas pela lei. Por outro lado, se a medição requer custos de transação mais elevados, outras formas de garantias, que não amparadas pela lei, como é o caso do desenvolvimento de mecanismos de reputação dos agentes envolvidos, podem ser utilizadas.

Barzel (2004) propõe a padronização dos atributos como forma de reduzir o comportamento oportunista dos agentes, além de diminuir o custo de adquirir informações a respeito dos atributos da mercadoria que está sendo comprada. Sendo assim, quanto maior a difusão e conhecimento acerca dos padrões de uma mercadoria, mais facilidade de mensuração dos atributos desse produto e, consequentemente, menos custos de transação incorridos. Isso possibilita que se estabeleça uma estrutura de governança menos integrada. Dessa forma, para Barzel (2005), a padronização de ativos é um procedimento que pode evitar disputas, eficaz para que os envolvidos na transação desenvolvam confiança e reputação.

\section{METODOLOGIA}

Em termos metodológicos o presente estudo tem abordagem qualitativa, é do tipo descritivo, com recorte temporal transversal. Para a coleta dos dados primários, realizou-se entrevista semiestruturada com os produtores agrícolas de uva e com representantes das empresas beneficiadoras da fruta - as vinícolas.

Quanto à localização geográfica, foi delimitada a região selecionada para o estudo a partir da divisão políticoadministrativa do IBGE. O Meio-Oeste catarinense está inserido na mesorregião Oeste catarinense, e os municípios selecionados para a pesquisa fazem parte da microrregião de Joaçaba, onde se concentram os maiores produtores estaduais de uva e vinho.

A partir dessa delimitação geográfica, foram selecionados os municípios que mais registraram valores na atividade vitícola na microrregião de Joaçaba nos últimos anos. Os principais municípios são: Tangará, Videira, Pinheiro Preto, Caçador, Fraiburgo, Água Doce, Rio das Antas, Ibiam, 
Salto Veloso e Iomerê (IBGE, 2015). Nesse sentido, o MeioOeste catarinense é caracterizado no presente estudo como sendo representados por esses dez municípios. Os dados da Epagri (2013) apontam a presença de 950 produtores de uva nos municípios selecionados. Em relação ao número de vinícolas destes municípios, dados indicam que existem 34 empresas que beneficiam a uva (SIMIONI, 2015).

Considerando a população dos produtores de uva como elevada, optou-se por realizar uma amostra não probabilística intencional. Segundo Marconi e Lakatos (1996), nesse tipo de amostragem o pesquisador tem interesse na ação ou opinião de determinados elementos da população, mas não representativos da amostra. Partindo disso, consideraram-se os seguintes critérios para selecionar a amostra dos produtores de uva: 1) Selecionar os produtores que fornecem uva para as vinícolas e que foram destacados por elas como fornecedores ou como principais fornecedores da empresa; 2) Selecionar produtores pela disponibilidade que os mesmos têm para responder o questionário.

Amparada nesses critérios, foram indicados, pelos representantes das vinícolas, 64 produtores, contudo parte significativa destes são do Rio Grande do Sul. Além disso, considerou-se, também, que algumas empresas, por regras internas, não puderam disponibilizar nomes de produtores. Dos 64 produtores, foram realizadas entrevistas com 24 deles. Não tendo indicações feitas pelos representantes das vinícolas, criou-se o segundo critério, ou seja, a disponibilidade dos produtores. Do segundo critério, foram selecionados 15 produtores, contabilizando um total de 39 entrevistas com produtores agrícolas. No caso das vinícolas, por possuir uma população relativamente pequena foram realizadas entrevistas com todas as 34 empresas As entrevistas foram realizadas entre os meses de agosto e outubro de 2015. Considera-se, ainda, como parâmetro da pesquisa a análise dos dados da safra 2014/2015.
Em relação ao método de análise, na presente investigação, os dados coletados foram analisados por intermédio do método de análise de conteúdo, adaptado para este estudo. Esse método indica três etapas básicas para análise de conteúdo: a pré-análise, a descrição analítica e a interpretação inferencial (BARDIN, 2004).

A pré-análise consiste em fazer a organização e classificação das ideias iniciais, com o objetivo de criar um roteiro preciso de cada etapa sucessiva das análises (BARDIN, 2004). Neste sentido, os dados obtidos foram organizados e alinhados de acordo com os pressupostos de cada teoria trabalhada, que orientaram, também, as questões contidas nas entrevistas. A etapa seguinte do método análise de conteúdo refere-se à descrição analítica. Nesta etapa, segundo Bardin (2004, p. 95), "[...] o material de documentos que constitui o corpus é submetido a um estudo aprofundado, orientado este, em princípio, pelas hipóteses e referencial teórico". Bardin (2004) indica a categorização como um fator relevante nessa etapa. Portanto, para essa pesquisa, foram atribuídas duas vertentes, cada qual com suas respectivas categorias. Para a TCT, três principais categorias foram propostas: atributos de transação, pressupostos comportamentais e estruturas de governança. Já para a TCM, identificou-se as categorias relacionadas à informação, padronização, mensuração e direitos de propriedade. O modelo teórico e esquema de análise resultante da formação dessas categorias é evidenciado na Figura 1.

A terceira fase do método de análise de conteúdo apontada por Bardin (2004) é a interpretação inferencial (BARDIN, 2004). Para a autora, nessa fase se busca as reais perspectivas daquilo que está sendo abordado, especificando ligações e aprofundando a ligação das ideias. Nessa fase, a análise foi realizada a partir da confrontação dos dados coletados na pesquisa de campo com os dados da pesquisa bibliográfica e documental.

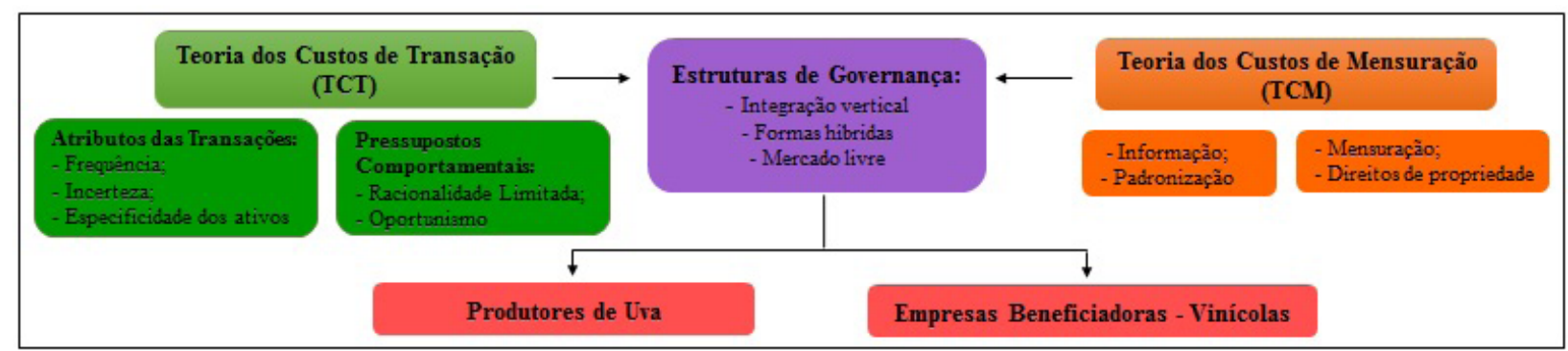

FIGURA 1 - Modelo Teórico do estudo de caso da Cadeia Vitivinícola do Meio-Oeste Catarinense: categorias de análise Fonte: Pesquisa de Campo (2015)

Organizações Rurais \& Agroindustriais, Lavras, v. 20, n. 3/4, p. 218-233, 2018 


\section{APRESENTAÇÃO DOS DADOS DA PESQUISA DE CAMPO}

\subsection{Segmentos Analisados}

\subsubsection{Produtores de uva}

O segmento da produção na região Meio-Oeste é formado por inúmeros produtores que atuam em pequenas e médias propriedades, concentrando em um mesmo terreno distintas atividades produtivas. Os 39 produtores selecionados produziram 3.433 mil quilos de uva, como visualizado no Quadro 1.

Constatou-se que os entrevistados atuam quase que exclusivamente no elo da produção. Tendo, ainda, $23 \%$ deles, equivalente a 9 produtores, que destinam alguma parte da uva para a comercialização in natura e 3 produtores, cerca de $8 \%$, que fazem a distribuição para mercados e atacadistas. Isso significa que quase toda uva colhida é destinada para as vinícolas, já que os mesmos usam uma pequena quantidade para o consumo próprio e para a venda in natura. O resultado disso é que há elevado nível de dependência entre produtores e empresas beneficiadoras.

\subsubsection{Empresas beneficiadoras - Vinícolas}

O elo dos beneficiadores é representado nessa cadeia produtiva pelas vinícolas. Na região Meio-Oeste configuram-se pela atuação em distintos segmentos, sendo que algumas delas participam de todas as etapas produtivas, enquanto que outras externalizam parcela de suas atividades, conforme visualizado no Figura 2.
As $32^{1}$ vinícolas analisadas quantitativamente foram responsáveis pela produção de 28.648 toneladas de uva processada na safra de 2015 , sendo que do total beneficiado $22 \%$ eram da própria vinícola e o restante era adquirido de outros produtores. Ademais, 6 delas adquirem $100 \%$ das uvas que beneficiam de terceiros, da mesma forma que outras 7 vinícolas só trabalham com uvas próprias para processamento, conforme Tabela 1 .

O volume de vinho produzido pelas empresas selecionadas naquela safra foi cerca de 16 milhões de litros. Neste caso, considerou-se a produção de 31 vinícolas, dado que a Empresa 2 preferiu não divulgar os dados referentes a sua produção. Buscando complementar o volume produzido, 15 empresas adquiriram o equivalente a 5.488 mil litros de vinho de outras vinícolas.

\subsection{Elementos das Transações: Pressupostos Comportamentais e Atributos das Transações}

As negociações entre produtor e processador tendem a ocorrer em todas as safras. No caso dos produtores notou-se que $20 \%$ dos entrevistados sempre transacionaram com a atual empresa; $21 \%$ dos produtores mantêm relações com a atual vinícola entre 20 e 35 anos; $31 \%$ dos entrevistados vendem sua produção para a atual empresa entre 5 e 19 anos. O resultado é que 28 produtores, o equivalente a $72 \%$ dos entrevistados, já se relacionam com a atual vinícola há mais de cinco anos.

${ }^{1}$ Duas vinícolas entrevistadas não apresentaram valores na produção de uva e vinho, para tanto, não serão consideradas nas questões quantitativas. Uma delas porque não comercializa mais vinho, todavia ainda é considerada vinícola para o Ministério da Agricultura, e por esse motivo, foi analisada. A segunda não apresentou valores produtivos por ser seu primeiro ano de funcionamento.

QUADRO 1 - Produtores, Municípios, e quantidade produzida (kg) de uva do Meio-Oeste de Santa Catarina, 2015

\begin{tabular}{|cccccccccccc|}
\hline $\mathrm{N}^{\circ}$ & Município & Produção & $\mathrm{N}^{\circ}$ & Município & Produção & $\mathrm{N}^{\circ}$ & Município & Produção & $\mathrm{N}^{\circ}$ & Município & Produção \\
\hline 1 & Pinheiro Preto & 170.000 & 11 & Videira & 18.000 & 21 & Tangará & 27.000 & 31 & Caçador & 22.000 \\
2 & Salto Veloso & 30.000 & 12 & Videira & 9.000 & 22 & Tangará & 80.000 & 32 & Caçador & 188.000 \\
3 & Pinheiro Preto & 210.000 & 13 & Videira & 40.000 & 23 & Tangará & 190.000 & 33 & Caçador & 50.000 \\
4 & Pinheiro Preto & 125.000 & 14 & Videira & 60.000 & 24 & Tangará & 60.000 & 34 & Caçador & 120.000 \\
5 & Pinheiro Preto & 95.000 & 15 & Videira & 155.000 & 25 & Tangará & 150.000 & 35 & Caçador & 70.000 \\
6 & Videira & 70.000 & 16 & Videira & 160.000 & 26 & Tangará & 160.000 & 36 & Caçador & 157.000 \\
7 & Videira & 70.000 & 17 & Videira & 136.000 & 27 & Tangará & 12.000 & 37 & Caçador & 85.000 \\
8 & Videira & 40.000 & 18 & Videira & 65.000 & 28 & Tangará & 44.000 & 38 & Caçador & 48.000 \\
9 & Videira & 37.000 & 19 & Videira & 220.000 & 29 & Caçador & 22.000 & 39 & Rio das Antas & 90.000 \\
10 & Videira & 33.000 & 20 & Videira & 75.000 & 30 & Caçador & 40.000 & & Total & 3.433 .000 \\
\hline
\end{tabular}

Fonte: Pesquisa de Campo (2015) 


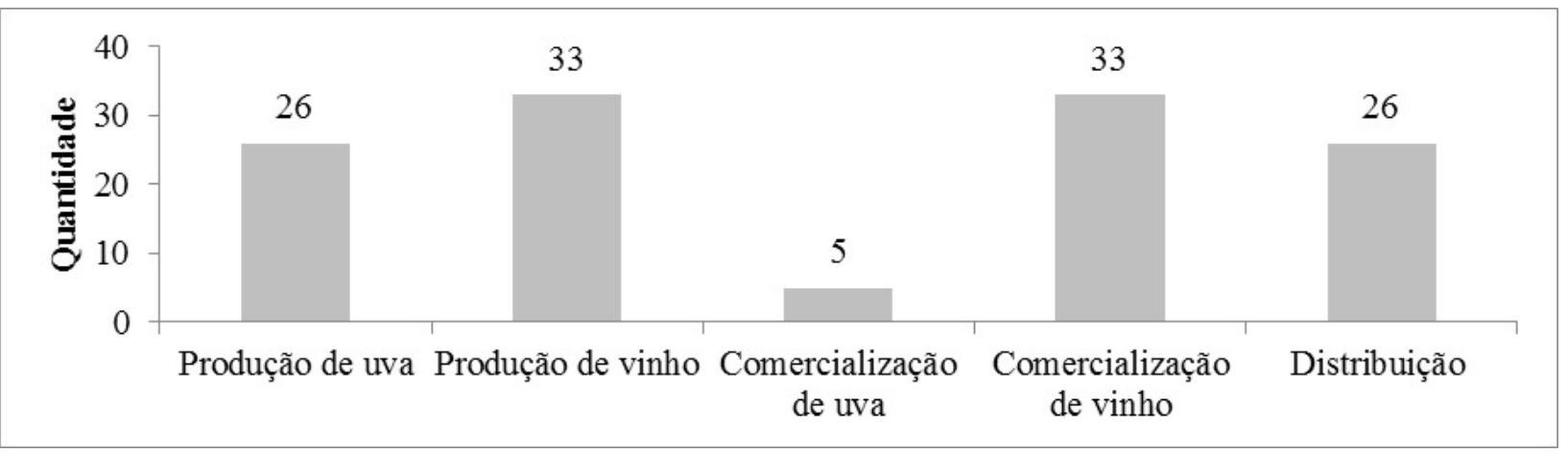

FIGURA 2 - Segmentos da cadeia produtiva vitivinícola que as vinícolas do Meio-Oeste de Santa Catarina atuam, 2015 Fonte: Pesquisa de Campo (2015)

TABELA 1 - Empresa, uva processada da vinícola e de terceiros $(\mathrm{kg})$, vinho produzido pela vinícola e adquirido de terceiros (1), do Meio-Oeste de Santa Catarina, 2015

\begin{tabular}{|c|c|c|c|c|c|c|c|c|c|}
\hline $\mathrm{N}^{\circ}$ & $\begin{array}{c}\text { Uva } \\
\text { processada }\end{array}$ & $\begin{array}{l}\text { Uva de } \\
\text { terceiros }\end{array}$ & $\begin{array}{c}\text { Vinho } \\
\text { produzido }\end{array}$ & $\begin{array}{l}\text { Vinho de } \\
\text { terceiros }\end{array}$ & $\mathrm{N}^{\circ}$ & $\begin{array}{c}\text { Uva } \\
\text { processada }\end{array}$ & $\begin{array}{l}\text { Uva de } \\
\text { terceiros }\end{array}$ & $\begin{array}{l}\text { Vinho } \\
\text { produzido }\end{array}$ & $\begin{array}{l}\text { Vinho de } \\
\text { terceiros }\end{array}$ \\
\hline 1 & 115.000 & 0 & 85.000 & 0 & 18 & 500.000 & 30.000 & 150.000 & 0 \\
\hline 2 & 650.000 & 280.000 & - & 0 & 19 & 150.000 & 4.500 & 117.000 & 45.000 \\
\hline 3 & 71.000 & 35.500 & 49.000 & 0 & 20 & 1.000 .000 & 600.000 & 750.000 & 1.500 .000 \\
\hline 4 & 1.000 .000 & 750.000 & 750.000 & 550.000 & 21 & 2.000 .000 & 2.000 .000 & 1.500 .000 & 0 \\
\hline 5 & 250.000 & 50.000 & 190.000 & 10.000 & 22 & 1.000 .000 & 1.000 .000 & 700.000 & 350.000 \\
\hline 6 & 140.000 & 0 & 110.000 & 0 & 23 & - & - & - & - \\
\hline 7 & 40.000 & 0 & 28.000 & 600.000 & 24 & 200.000 & 100.000 & 170.000 & 0 \\
\hline 8 & 200.000 & 150.000 & 142.000 & 30.000 & 25 & 2.044 .000 & 2.044 .000 & 1.470 .000 & 0 \\
\hline 9 & 800.000 & 800.000 & 600.000 & 400.000 & 26 & 500.000 & 150.000 & 400.000 & 0 \\
\hline 10 & 275.000 & 125.000 & 175.000 & 0 & 27 & 100.000 & 25.000 & 70.000 & 0 \\
\hline 11 & 2.500 .000 & 1.500 .000 & 2.000 .000 & 1.000 .000 & 28 & 250.000 & 125.000 & 150.000 & 30.000 \\
\hline 12 & 250.000 & 20.000 & 180.000 & 50.000 & 29 & 190.000 & 0 & 190.000 & 0 \\
\hline 13 & 200.000 & 0 & 150.000 & 0 & 30 & 6.000 .000 & 6.000 .000 & 50.000 & 0 \\
\hline 14 & 80.000 & 60.000 & 70.000 & 5.000 & 31 & 175.000 & 0 & 120.000 & 0 \\
\hline 15 & 850.000 & 425.000 & 600.000 & 150.000 & 32 & 7.000 .000 & 6.000 .000 & 5.000 .000 & 750.000 \\
\hline 16 & 78.000 & 15.300 & 56700 & 18.500 & 33 & 20.000 & 0 & 13.000 & 0 \\
\hline 17 & 20.000 & 20.000 & 14.500 & 0 & 34 & - & - & - & - \\
\hline Total & & & & & & 28.648 .000 & 22.309 .300 & 16.050 .200 & 5.488 .500 \\
\hline
\end{tabular}

Fonte: Pesquisa de Campo (2015)

De todos os entrevistados, 37 acreditam que a frequência maior nas negociações pode gerar ganhos como: confiança, amizade, parceria, fidelidade nas negociações, conhecimento, ajuda mútua, maior credibilidade e bom relacionamento. $\mathrm{O}$ conjunto de benefícios desenvolvidos com o aumento no número de transações entre as partes tende diminuir as chances de oportunismo e reduzir a limitação cognitiva dos agentes.
Quanto mais a gente negocia com a cantina maior o conhecimento que a gente tem dela. (...) fornecer a uva por tanto tempo ajuda a fidelizar a relação (Prod.1).

O tempo que produtores e vinícolas mantem relações pode ser explicado por alguns elementos. Manter uma relação permanente e amigável pode conservar as negociações entre as partes. Apesar disso, não é só uma 
boa relação que estimula as trocas entre os dois segmentos. $\mathrm{Na}$ visão de 36 produtores, o que equivale a 92\% dos entrevistados, confiança e reputação no comprador da produção são fundamentais nesta relação. Outros fatores que influenciam o produtor a transacionar com a atual vinícola é o preço que a vinícola paga pela fruta (apontado por $56 \%$ dos entrevistados), tempo que se relaciona com o comprador ( $56 \%$ do total de entrevistados), e proximidade geográfica (54\% dos entrevistados).

Ainda que as relações entre produtor e processador ocorram a tempo suficiente para desenvolver mecanismos sociais, é possível verificar que existem incertezas relacionadas às transações e há racionalidade limitada dos produtores quanto a algumas decisões das vinícolas. A principal incerteza presente no segmento da produção está relacionada ao clima, que é um indicador de qualidade da uva e, muitas vezes, do preço da fruta. A limitação cognitiva está relacionada à continuidade da transação na safra seguinte.

Um dos principais problemas que eu vejo é em relação à volatilidade na necessidade da uva (Prod. 38).

A gente não tem garantia de que a cantina vai comprar nossa uva na safra seguinte, mas até agora sempre precisaram comprar de outros produtores (Prod.4).

Nestes termos, mesmo havendo atributos como a incerteza e pressuposto comportamental como a racionalidade limitada, a frequência das transações tende a gerar mecanismos de reputação que diminuem o nível de insegurança e a limitação cognitiva dos agentes, como destacado por Zylbersztajn (2005). Desta forma, diante da inexistência de contratos, a confiança torna-se o principal fator que baliza as relações produtor-processador, capaz de inibir comportamentos oportunistas e estimular a parceria e fidelidade entre as partes.

No caso das 25 vinícolas que adquirem uva de terceiros, as transações com os produtores ocorrem todos os anos, podendo variar a quantidade de fruta entregue de acordo com a necessidade da vinícola, com a produção do fornecedor ou com o volume negociado por ambos no início da safra. Das vinícolas que mantêm relações com terceiros, pode-se dizer que as transações entre ambos são recorrentes, pelo fato de ocorrerem geralmente todos os anos e elevadas vezes na mesma safra.

Por sua vez, a compra de vinho de outras cantinas ocorre de acordo com a necessidade e demanda da vinícola. Em 2015, a compra de vinho de terceiros foi realizada por 15 vinícolas. Segundo relatos, as transações tendem a ocorrer de 3 a 4 vezes ao ano. Nesse caso, a compra de vinho pode ser considerada esporádica, porque depende da necessidade da cantina, ao passo que pode nem ocorrer em determinado ano.

$\mathrm{O}$ número de transações pode ter influência nas relações entre produtor e processador. O resultado é que a maior frequência nas relações entre os segmentos pode gerar benefícios como: confiança, conhecimento, fidelidade, padronização, segurança, além disso, o fornecedor passa a compreender as necessidades da vinícola.

(...) Se a gente conhece o fornecedor e confia nele pode acontecer da gente fechar mais negócios, nós podemos fazer parceria para outras safras, isso pode gerar melhoria nos preços, já que há conhecimento mútuo (Emp.5).

Conhecimento, confiança e fidelização, a gente trabalha com os mesmos fornecedores há cinco anos, temos uma boa parceria (Emp.18).

Mesmo negociando com produtores e outras cantinas regularmente, alguns entrevistados relatam que ainda existem incertezas nas negociações, sendo a principal delas relacionada à qualidade dos produtos adquiridos. Apesar das partes se conhecerem, pode ocorrer da safra não ter os padrões esperados, prejudicando as características da uva e do vinho negociados. O clima foi um elemento levantado pelos entrevistados que pode comprometer a qualidade da safra e acarretar incertezas, principalmente quanto à entrega da produção.

A maior dificuldade e incerteza que a gente tem é lidar com produtos que dependem do tempo para ter qualidade (Emp.3).

A incerteza quanto à padronização dos produtos adquiridos de terceiros também foi apontada pelos representantes das vinícolas. No caso da uva, os diferentes estados de maturação de uma mesma variedade podem ocasionar distintos graus glucométricos. A insegurança prevalece quanto ao vinho, já que a vinícola fornecedora pode realizar as etapas do processo de fabricações em distintos períodos ou utilizando produtos diferentes. Isso faz com que o vinho comprado tenha características distintas do vinho da própria vinícola. O preço da uva também é um elemento de incerteza para algumas vinícolas, pelo fato de que o mesmo só é negociado quando a fruta chega a vinícola, ajustado de acordo com a qualidade do produto.

A cantina se preocupa bastante com a padronização. (...) Todos os vinhos de uma mesma variedade precisam ter as mesmas características (Emp.7).

(...) Qualidade e padronização, nós só temos um fornecedor de casca dura, por exemplo, pra deixar a produção padronizada (Emp.17). 
(...) a maior incerteza é em relação ao preço, que só é negociado na hora da colheita e de acordo com a qualidade da uva (Emp.22).

Ainda que tenham sido apresentados elementos permeados por incertezas na relação como os problemas climáticos que prejudicam a uva negociada, além do preço, qualidade e padronização dos produtos, alguns entrevistados apontaram que diante de tais incertezas a relação com os produtores é de confiança, pelo tempo em que os mesmos transacionam.

Mesmo diante do elevado número de vezes que as negociações ocorrem, $61 \%$ das vinícolas nunca tiveram problemas ou situações de oportunismo por parte dos fornecedores, segundo seus representantes. Apesar da ausência de contratos que salvaguardem os direitos dos envolvidos nas transações, as partes não podem desconhecer os aspectos da negociação. Na maioria das transações, devido ao tempo que se relacionam, todos já conhecem os procedimentos a seguir e as exigências da vinícola.

Além da frequência e incerteza nas negociações, o último atributo das transações é a especificidade dos ativos utilizados no processo produtivo. A maioria dos entrevistados afirmou que dificilmente as máquinas e equipamentos, utilizados principalmente na fabricação e envase do vinho, podem ser utilizados em outras atividades que não estejam relacionadas à produção de bebidas ou fabricação de geleias. Assim sendo, máquinas como de controle de temperatura, desengaçadeira, envasadora, rotuladora, centrífugas e tanques de fermentação são específicas para a produção de bebidas.

Não tem como utilizar essas máquinas e equipamentos em outras atividades, a não ser pra produção de outras bebidas (Emp.15).

Além disso, na presença de especificidade de ativos, a integração vertical pode ser um arranjo institucional eficiente para governar as transações, pelo fato de que limita a chance de comportamentos oportunistas ocorrerem (WILLIAMSON, 1985). Desta forma, a vinícola tem a possibilidade de controlar e monitorar seus ativos específicos.

\subsection{Mensuração, Padronização e Controle}

A qualidade dos produtos é posta a prova assim que a uva e o vinho chegam à vinícola. Inicia-se a partir daí um processo de verificação e controle que compreende etapas de inspeção e análise da qualidade. No caso da uva, são realizadas análise do grau, acidez, densidade e ph, sendo que quanto ao vinho adquirido de outras vinícolas, é feita análise bioquímica. Todavia, antes de comprar a bebida são realizadas análises das amostras dos vinhos, buscando, além da padronização, qualidade no produto.

(...) Quando a gente chega na cantina eles (funcionários da vinícola) já tiram as lonas da carga e olham como está a uva. Depois eles pesam a carga e tiram o grau (Prod.1).

No caso da uva, é realizada a análise do grau glucométrico, acidez, densidade e ph. Para o vinho, são feitas análises bioquímicas (Emp.33).

O pagamento da produção muitas vezes é realizado de acordo com o grau glucométrico da fruta, esse fator tende a uniformizar a uva recebida na vinícola, isso porque os produtores, visando conseguir um melhor preço, passam a colher a uva quando a mesma estiver madura. Realizar a colheita em seu melhor estado de maturação induz a um processo de padronização da fruta, que é favorável tanto para o produtor, quanto para a cantina que produz uma bebida de melhor qualidade. Nos casos em que a vinícola precisa comprar vinho, a análise bioquímica é a forma de controle utilizada para assemelhar as características dos vinhos produzidos com os adquiridos de terceiros.

A não existência de contratos para salvaguardar as relações entre produtores de uva e vinícolas faz com que as negociações baseiem-se na confiança e reputação das partes. Além disso, dada a elevada demanda pela fruta por parte das cantinas da região, os produtores individuais de uva tem consciência que oferecendo um produto de qualidade e que satisfaça as necessidades da vinícola poderão vir a negociar outras vezes. Apesar disso, frequentemente os produtores de uva do MeioOeste apontaram que as garantias são estabelecidas, informalmente, através do acordo verbal, caso a cantina venha a necessitar da uva na safra seguinte.

A falta de contrato impede que a gente exija qualquer coisa da cantina, (...) os problemas são resolvidos sempre por nossa conta (Prod.1).

Nunca teve garantia, mas até então sempre faltou uva pra vinícola, o que faz com que eles precisem de nós (Prod.4).

Conforme verificado, não há garantias por parte da vinícola de que estes ficarão com a fruta na safra seguinte. Isso porque, dentre outros fatores, a cantina não assegura que o volume processado e as variedades beneficiadas serão as mesmas nas safras seguintes. Não se comprometendo com possíveis contratos formais que venham a lhe impor alguma punição no caso de não necessitar mais da produção de um dos fornecedores. Por outro lado, os entrevistados afirmam que muitas vezes o vinicultor dá sua palavra de que voltará a negociar com o produtor na safra seguinte. Desta forma, é possível 
verificar que a inexistência de contratos é uma opção das vinícolas, isentando a mesma de possíveis obrigações com seus fornecedores.

\subsection{Internalização e Externalização das Atividades}

A opção da vinícola de produzir integralmente verticalizada ao invés de externalizar as atividades requer que a mesma possua a estrutura física para produção e processamento, máquinas e equipamentos e as competências humanas para realizar as atividades. Os benefícios da produção interna são principalmente: qualidade e padronização dos produtos, controle das etapas produtivas, redução de custos, garantia de contar com a matéria-prima e com as variedades que necessitam e adaptações mais rápidas às mudanças do mercado.

(...) a gente colhe a uva de melhor qualidade, as piores uvas ficam para vinhos de segunda. Assim a gente consegue controlar melhor a produção e padronizar os produtos, melhorando a qualidade por um preço menor (Emp.22).

(...) certeza de ter a matéria-prima, também pelo menor custo ligado a produção interna, maior controle da produção e garantia de qualidade do produto (Emp.11).

(...) qualidade, conseguimos controlar melhor o preço do produto, e acompanhar os efeitos da demanda do mercado (Emp.16).

Apesar dos pontos favoráveis a internalização de atividades, dois representantes afirmaram que os benefícios de produzir por conta própria são restritos, principalmente no que se refere à produção de uva, sendo para estes, mais vantajoso comprar de terceiros.

(...) Atualmente é melhor contratar, porém o que já se tem (parreiras) não compensa ser tirado, mas não vale mais a pena investir em novos parreirais (Emp.12).

Quando a vinícola escolhe externalizar a produção ela pode se deparar, dentre outros fatores, com uma redução da capacidade produtiva, dependência de fornecedores, queda da demanda por mão de obra e, consequentemente, diminuição nos custos. O principal fator que leva as vinícolas a externalizar é a ausência de produção própria ou quando há insuficiência da mesma. Nestes casos, as empresas passam a comprar uva de outros produtores. Já o vinho é adquirido de outras cantinas quando a produção própria não supre a demanda.

A vinícola compra de terceiros quando não tem espaço pra produzir o produto por conta própria (Emp.26).

Nós compramos de terceiros quando (...) não produzimos suficiente (Emp.28).
Além da necessidade, muitas vezes os custos de comprar de terceiros são menores do que os custos de produzir internamente. Nestes casos a vinícola opta por externalizar a produção de atividades que incorrem em custos mais elevados, realizando as atividades que lhe são mais rentáveis ou que possuem mais competências para realizar. Aliado a isso, a dificuldade de acesso à mão de obra para atuar na atividade também induz a vinícola a adquirir os produtos de terceiros.

Comprar vinho de terceiros torna-se mais barato do que produzir internamente. A produção interna tem elevados custos de produção (Emp.7).

A dificuldade que a gente tem de conseguir mão de obra para trabalhar nas atividades nos leva a terceirizar a produção (Emp.15).

Não há riscos nem custos trabalhistas. O preço final do vinho está baixo (Emp.23).

Outro fator que leva a empresa externalizar é a falta de condições adequadas para produzir determinado produto. Como é o caso da cultivar Bordô que não tem a produtividade desejada pelos produtores e vitivinicultores e, ainda, não supre a necessidade das vinícolas pela variedade. A produção enxuta também induz a externalização de atividades, sendo uma opção para as vinícolas que procuram reduzir o volume estocado.

(...) quando não consegue produzir a variedade de uva que precisamos, como é o caso da Bordô, por algum problema climático ou de adaptação. No caso do vinho, quando realmente precisam da bebida (Emp.16)

Melhor comprar de terceiros. Uma das razões é pela redução dos estoques (Emp.9)

Levando em conta que das 32 vinícolas analisadas no item da produção $78 \%$ delas adquiriram uva e $45 \%$ compraram vinho de terceiros na última safra, os entrevistados foram questionados quanto aos critérios de seleção de fornecedores. Constatou-se que a maioria das vinícolas se preocupa com a qualidade e padronização dos produtos. Considera-se desde o nível de coloração e maturação das bagas, o sabor do vinho, assim como a higiene e cuidados com os tratamentos aplicados nos parreirais.

A gente leva em conta a qualidade nos produtos oferecidos e a confiança nos parceiros. (...) Os fornecedores da empresa são os mesmos desde o primeiro ano de funcionamento. Nós levamos em conta se eles fazem acompanhamento técnico da produção, controle no uso de agrotóxicos. (...) também levamos em conta o grau de doçura da uva (Emp.3). 
Nós procuramos analisar a qualidade, o grau babo, (...) os cuidados com os tratamentos (Emp.21)

Além da qualidade, os vinicultores também julgam ser importante a seriedade, parceria, confiança e fidelidade dos produtores. Estando em posse desses atributos, conhecendo os fornecedores e seguindo as normas e exigências da vinícola, principalmente no que se refere à qualidade e padronização, os entrevistados afirmaram não haver outros empecilhos que impeçam as vinícolas a transacionar com os fornecedores.

(...) cumprimento com a quantidade e qualidade que se propôs a entregar para a cantina (Emp.14).

A gente busca produtores com seriedade e confiança. Como a gente conhece os produtores da região, sabe quem é de confiança (Emp.19).

Hoje a gente não tem mais critério ou exigência para selecionar os fornecedores, porque a gente já compra dos mesmos produtores há 20 anos (Emp.28).

A gente conhece a maioria dos produtores da região, (...) sabe quem é bom fornecedor. (Emp.34).

Estes mecanismos de reputação são fundamentais pelo fato de que não há qualquer tipo de contrato formal que ampare as relações entre vinícolas tanto com os fornecedores de uva, quanto com outras vinícolas. Esse fator exige-se um mínimo de confiança entre as partes, já que $22 \%$ das vinícolas não produzem uva, trabalhando somente com matéria-prima de terceiros, assim como 59\% das cantinas, mesmo tendo sua própria matéria-prima, compram uva de outros produtores. Da mesma forma, que $47 \%$ das vinícolas compram o vinho de outras cantinas para complementar a produção própria.

Nesse sentido, as vinícolas do Meio-Oeste podem ser caracterizadas por atuarem tanto integradas verticalmente (WILLIAMSON, 1985, 1996), como por meio de relações híbridas (MÉNARD, 2004). As formas híbridas são apresentadas na rotina das empresas como quase integração vertical de subcontratantes. No caso das vinícolas analisadas que se enquadram neste tipo de relação, essas assumem a configuração de arranjos menos formais.

Ainda, neste caso, dada a ausência de salvaguardas contratuais, os mecanismos de reputação são comumente utilizados na região pelos vinicultores, como forma de limitar atitudes oportunistas. Isso porque, conforme Ménard (2004), a medida que as partes se conhecem, aumenta o uso de mecanismos informais, como reputação, confiança e disseminação de informações, utilizados como inibidores de atos inadequados dos agentes.

\subsection{Análise dos Dados}

\subsubsection{Estruturas de governança}

A partir dos dados primários coletados com a pesquisa de campo, constatou-se que todos os produtores de uva entrevistados vendem, se não parcela, o total de sua produção para as vinícolas da região. A decisão de externalizar as atividades por parte da vinícola está ligada ao fato de que $19 \%$ delas não possuem parreirais, o que induz a vinícola a adquirir uva de terceiros para produzir vinho. Há, ainda, as cantinas que adquirem uvas de outros produtores e vinhos de outras vinícolas pra complementar a produção própria.

Outro fator que leva a vinícola a externalizar a produção é pelo fato de que os custos de transação externos a ela são menores do que os internos, sendo mais vantagem adquirir de terceiros. Isso remete as colocações de Coase (1937) e Williamson $(1985,1996)$ de que na presença de custos internos elevados de coordenação ou governança, há motivos para as empresas manterem relações com fornecedores. Das 32 vinícolas analisadas nos itens quantitativos, 25 delas, o que equivale a $78 \%$, adquiriram uva de produtores agrícolas e 15, cerca de $47 \%$, compraram vinho de outras cantinas, sendo que $44 \%$ delas adquiriram uva e vinho de terceiros. Isso demonstra a interdependência entre os dois segmentos analisados.

Apesar da grande maioria das vinícolas manterem relações com fornecedores de uva e vinho, 19\% delas atuaram somente com produção própria. A integração de atividades dentro da estrutura da empresa facilita a adaptação às mudanças, além de possibilitar que as mesmas sejam feitas assim que demandadas, evitando consultas com parceiros, conforme apontado por Williamson (1996).

Conclui-se que as estruturas de governança comumente encontradas na região Meio-Oeste de Santa Catarina são integração vertical (WILLIAMSON, 1985, 1996) e as formas híbridas (MÉNARD, 2004), conforme verificado na Figura 3. No primeiro caso, têm-se a produção e o processamento da uva sendo realizados pela própria vinícola, o que possibilita um controle maior das etapas e adaptações rápidas as demandas do ambiente. As formas híbridas, por sua vez, compreendem as relações estabelecidas com terceiros, caracterizadas pela ausência de contratos na região em estudo, sendo essa estrutura adotada na ausência ou insuficiência de produção própria ou para redução de custos. 


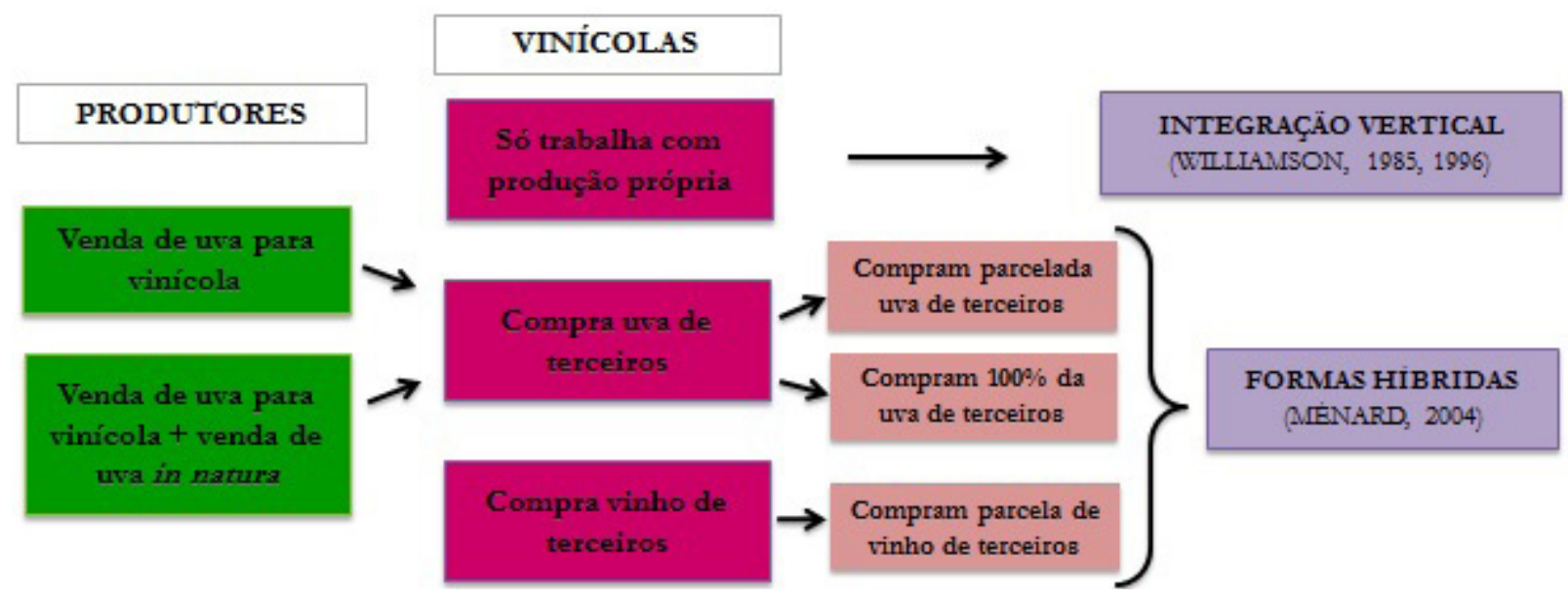

FIGURA 3 - Tipos de relações estabelecidas entre os produtores de uva e as vinícolas do Meio-Oeste de Santa Catarina Fonte: Elaborado pela autora a partir dos dados coletados com a pesquisa de campo (2015)

\subsubsection{Teoria dos Custos de Transação}

Na ausência de salvaguardas contratuais, as relações entre os produtores de uva e as vinícolas no Meio-Oeste catarinense são sustentadas pela confiança entre as partes. Mesmo sabendo da existência de oportunismo nas relações (WILLIAMSON, 1985; MÉNARD, 2004), as partes afirmam ter um bom relacionamento e parceria. Isso se deve também pelo fato de que muitos dos produtores transacionam com o atual comprador da produção a um longo período. Soma-se a isso o fato da região ser pequena e a maioria das vinícolas estarem concentradas em três municípios, o que promove a difusão de informações sobre a produção, produtores e vinícolas. Nesse caso, segundo Zylbersztajn (2005), acordos informais são amparados por salvaguardas reputacionais e outros mecanismos sociais que tendem a inibir pressupostos comportamentais como o oportunismo.

Assim como o oportunismo, a racionalidade limitada é outro pressuposto comportamental que influencia as transações. A incapacidade de prever todos os aspectos envolvidos nas negociações pode estar associada ao ambiente em que a vinícola está inserida ou ao comportamento dos agentes (WILLIAMSON, 1985, 1996). Na perspectiva da vinícola a limitação cognitiva está relacionada às incertezas em relação ao comportamento dos produtores. Pelo âmbito dos produtores isso se reflete nas decisões dos vinicultores, relacionadas às variedades exigidas, pelo preço pago pela fruta e continuidade das transações na safra seguinte.

Juntamente com a limitação cognitiva, a incerteza, um dos atributos das transações, reflete-se nos segmentos entrevistados pela assimetria de informações (WILLIAMSON, 1985). As principais incertezas ligadas à atividade, sentidas pelos dois segmentos analisados, são em relação ao clima, a qualidade da uva, o preço da fruta e da necessidade de uva e vinho na safra seguinte. Isso porque, não há como antecipar, prever ou assegurar que a demanda pela fruta ou pela bebida serão mantidas ou aumentadas no próximo ano, ou que o clima seja favorável, que implica na maturação da uva e consequentemente no preço da fruta.

Em alguns casos, as incertezas e as chances de ocorrerem problemas nas negociações são reduzidas pelo aumento nas transações, conforme apontado por Williamson $(1985,1996,2002)$. Nesta situação, as transações ocorrendo com maior frequência tendem a aumentar o conhecimento, parceria e fidelidade entre os segmentos. Constatou-se que as transações das vinícolas com produtores são recorrentes, pois tendem a ocorrer todos os anos, diversas vezes em uma mesma semana durante a safra. Não obstante, as transações com outras vinícolas são caracterizadas como esporádicas, dado que tendem a ocorrer com menos frequência, de acordo com a necessidade da vinícola.

Mesmo na presença de elementos que assegurem um relacionamento favorável entre os segmentos, visualizou-se com as entrevistas que pode haver casos em que a vinícola deixa de adquirir a uva de determinado produtor. Neste caso, o cancelamento do fornecimento deu-se por que a vinícola encerrou suas atividades, porém, mesmo com o fechamento da empresa os produtores que 
até então eram seus fornecedores foram encaminhados para outra cantina que passou a comprar as uvas desses produtores. Apesar da solução positiva, pode ocorrer da fruta, na ausência de novos compradores, permanecer no parreiral por tempo superior ao necessário, o que reduz sua qualidade, podendo ocorrer até perda da produção. A dificuldade de reempregar o ativo sem renúncia do seu valor produtivo demonstra que a uva pode ser considerada um ativo específico, conceituado por Williamson (1996).

Contudo, a existência de significativa quantidade de fornecedores, principalmente no caso dos produtores de uva do tipo mesa, induz que o ativo não tem elevado grau de especificidade. Nesses termos, o ativo é específico para o produtor, mas pode não ser específico para a vinícola que o adquire. No caso do vinho, notadamente nas variedades finas, pode-se considerar uma maior especificidade, dado que o conhecimento envolvido é maior.

Em suma, verificou-se, a partir do referencial teórico da TCT, que as formas de governar as transações da cadeia vitivinícola do Meio-Oeste catarinense são: integração vertical e formas híbridas, estruturas de coordenação destacadas na teoria por Williamson (1985) e Ménard (2004). Pelo fato de haverem inúmeros substitutos, produtores e vinícolas, para corrigir e disciplinar os problemas que possam ocorrer com os fornecedores a chance de haver comportamento oportunista é reduzida e a racionalidade não é tão limitada. O que possibilita o aumento do controle, conforme proposto por Williamson (1985). A reputação desenvolvida e o interesse dos fornecedores de permanecer transacionando com o atual comprador é o que minimiza as incertezas e o oportunismo nas relações.

No que concerne aos ativos, estes podem ser considerados específicos notadamente nos casos em que há produção de variedades de uvas e vinhos finos. Além disso, podem ocorrer casos em que o ativo é específico para o produtor, não sendo específico para a vinícola. Apesar disso, não há qualquer indicativo de que as vinícolas prefiram um ou outro tipo de governança, já que a vinícola vai optar entre integrar verticalmente ou manter relações com fornecedores a partir da necessidade ou capacidade de adaptação às suas demandas.

Dessa forma, havendo a possibilidade de produzir por conta própria, sem maiores custos, a vinícola opta pela integração vertical, o que lhe possibilita adaptação mais rápida das demandas e maior controle. No caso de haver impossibilidade de produzir toda a uva ou vinho necessários, a vinícola passa a manter relações com fornecedores, podendo assim, reduzir custos e estoques, o que justificaria a escolha das formas híbridas.

\subsubsection{Teoria dos Custos de Mensuração}

A vinícola que está adquirindo a uva e o vinho tem na mensuração dos atributos desses produtos uma forma de controle, voltada para garantir os requisitos técnicos exigidos (visual, peso, maturação e grau). Isso porque, na maioria dos casos constatou-se que o pagamento era feito a partir dessas características técnicas dos produtos. Desse modo, os direitos de propriedade (BARZEL, 2002) dos envolvidos são garantidos a partir dos resultados da mensuração dos atributos dos ativos. Enquanto que para a vinícola a mensuração viabiliza a compra da uva e do vinho, para os fornecedores ela serve de balizador, avaliando a capacidade de adequação as especificações exigidas pela vinícola compradora.

Outro fator que nos remete a mensuração quando se analisa o setor é a importância dada à padronização dos produtos produzidos pelas vinícolas e comprados de terceiros. No caso dos produtores a padronização está voltada para o período da colheita, isso porque colhendo a uva em bom estado de maturação consegue-se um preço final melhor. $\mathrm{O}$ que é benéfico também para a vinícola que recebe a fruta de melhor qualidade e passa a utilizar menos açúcar na fabricação do vinho. A padronização também é considerada essencial nos casos de compra de vinho. A compra da bebida de um só fornecedor, por exemplo, possibilita que se comercializem vinhos com as mesmas características, evitando variações significativas de saber de vinhos de mesma variedade. De acordo com Barzel (2004, 2005) quanto maior o conhecimento acerca dos padrões de uma mercadoria, mais facilidade de mensuração dos seus atributos e, por conseguinte, menos custos de transação incorridos. O que possibilita a adoção de uma estrutura de governança menos integrada.

A informação a disposição das partes torna-se fundamental na decisão de internalizar ou terceirizar a produção, segundo Barzel (2005), e para a garantia dos direitos de propriedade, de acordo com Zylbersztajn (2005). No setor vitivinícola, verificou-se que o processo de mensuração pode ser considerado recorrente durante a safra, notadamente nas transações de uva. Tendo como consequência a geração de informação (a respeito da qualidade da uva e do vinho, e sobre reputação do produtor e da vinícola com as quais transacionam) a respeito dos produtos e dos produtores.

Em caso de dificuldade de mensuração dos atributos dos ativos, é melhor que os produtos estejam sob o domínio das vinícolas, como destaca Barzel (2005) e Zylbersztajn (2005). É o que ocorre com as uvas e vinhos finos. Nesses 
casos é preferível que a vinícola produza por conta própria, dado que é necessário maior acompanhamento, tanto nos parreirais, quanto no processo de produção da bebida. Assim, pelo fato de serem produtos específicos é melhor que os mesmos sejam mantidos sob os cuidados da própria vinícola, preservando as características e buscando o padrão que se espera. Aliado a isto, produzindo internamente a vinícola consegue garantir seus direitos privadamente, além de dispor de maior informação a respeito dos produtos e processos, mantendo um nível mais elevado de padronização. Por outro lado, no caso das uvas e vinhos comuns, dado o maior acesso a informação, facilidade de mensuração e padronização dos ativos, é preferível que os mesmos sejam adquiridos de terceiros, já que neste caso os mecanismos de reputação social tendem a inibir problemas nas transações.

A hierarquia das atividades dentro da estrutura da vinícola justifica-se, portanto, diante da possibilidade de controle das etapas do processo e das características finais do produto. Do contrário, controlar tais elementos fora da cantina dificultaria a garantia dos direitos de propriedade, pelo fato de que há limitação de informações a respeito dos produtos transacionados. Diante da necessidade das vinícolas de obter os produtos e do seu baixo custo, praticado por alguns fornecedores, a cantina pode preferir comprar uvas e vinhos de variedades mais comuns, que possuem menor valor agregado. Isso porque, as informações sobre os processos são mais difundidas, somadas ao fato de que há maior facilidade de padronizar e mensurar seus atributos.

\section{CONSIDERAÇÕES FINAIS}

O presente estudo discutiu as relações existentes entre os segmentos produtor e processador da cadeia vitivinícola do Meio-Oeste do estado de Santa Catarina, a partir das estruturas de governança adotadas. Para isso, foram apresentadas categorias de análise destacadas das abordagens da TCT e TCM. Na pesquisa de campo foram realizadas 39 entrevistas com produtores e $34 \mathrm{com}$ representantes das empresas beneficiadoras. A análise dos dois segmentos, a partir da pesquisa de campo, possibilitou a confrontação com o aporte teórico selecionado.

No que se refere aos custos de transação, os elementos presentes na referida teoria, destacados nas categorias de análise, foram tomados para a análise do setor vitivinícola. Levando isso em conta, a especificidades dos ativos no setor vitivinícola do Meio-Oeste de Santa Catarina se deu no âmbito locacional, temporal, físico, humano e de marca. A frequência foi recorrente quanto à compra de uva, e esporádica quando relacionada ao vinho. Acrescenta-se, ainda, o fato de que mesmo diante de negociações recorrentes, ainda está presente a condição de incerteza, resultante de fatores climáticos que influenciam na qualidade da uva e, consequentemente, no preço da fruta, além das oscilações de demanda que repercute na continuidade das transações na safra seguinte. Ademais, há limitação de informações por parte da vinícola relacionada ao comportamento dos produtores, e pelos produtores quanto às decisões tomadas pelas vinícolas. Todavia, mesmo diante da assimetria de informações, não foi constatado nenhum comportamento oportunista, tanto por parte dos produtores, como das vinícolas, principalmente devido a existência de mecanismos de reputação social que tendem a inibir comportamentos inadequados.

Dessa forma, na presença de especificidade de ativos, aliado à frequência recorrente com produtores e esporádica com outras vinícolas, à incerteza e racionalidade limitada e a ausência de comportamento oportunista, justifica-se a escolha das vinícolas pela integração vertical e pelas formas híbridas como estruturas de governança utilizadas na região. No caso de haver especificidades de ativos, incerteza e racionalidade limitada, é preferível que se integrem verticalmente as atividades. Tendo ausência de comportamento oportunista e aumento da frequência nas negociações, a vinícola pode optar por adquirir os produtos de terceiros. Entretanto, como visualizado no setor vitivinícola da região, a maioria das vinícolas não adota uma ou outra forma de coordenação individualmente, mas as duas simultaneamente.

Em relação aos custos de mensuração, elementos como direitos de propriedade, mensuração dos atributos, informação e padronização foram analisados. A mensuração ocorre no caso de atributos como peso, maturação e grau brix e babo da uva; no caso do vinho é realizado o controle de acidez, densidade e ph. A padronização nesse caso é marcada por significativos níveis de conformidade com as exigências técnicas do comprador. Nesse caso, os produtores tendem a oferecer um produto com as normas estabelecidas pela vinícola, especificamente no que se refere à maturação do produto.

Há acesso à informação entre os segmentos, principalmente relacionada à produção de uvas e vinhos de mesa. Além disso, há difusão de informações a respeito dos produtores e vinícolas, dado que a região é consideravelmente pequena e a maioria das empresas analisadas estão concentradas em três municípios, estimulando a utilização de mecanismos de reputação e inibindo atitudes oportunistas. 
Os mecanismos de reputação são utilizados como forma de garantir os direitos quando a vinícola opta por transacionar com fornecedores. Por outro lado, quando ela escolhe concentrar suas atividades dentro da sua estrutura produtiva seus direitos são garantidos privadamente.

Assim, sendo possível mensurar os atributos, tendo os direitos de propriedade dos produtores e cantinas estabelecidos, tendo acesso à informação entre as partes e sob um nível satisfatório de padronização, a opção por adotar as formas híbridas como estrutura de governança apropriada para as vinícolas. Do contrário, diante da dificuldade de mensuração dos atributos, de garantia dos direitos de propriedade, de acesso a informação sobre as transações, e com baixo nível de padronização dos produtos, é preferível que a estrutura de governança adotada pela vinícola seja a integração vertical.

Diante do exposto, foi possível notar que as relações entre os segmentos produtor e processador da cadeia vitivinícola do Meio-Oeste de Santa Catarina são praticadas por meio da internalização das atividades na vinícola, e de sua parceria com o segmento produtor de uva. Nesse contexto, são adotadas as estruturas de governança integração vertical e formas híbridas. Essas relações tendem a ocorrer com maior frequência quando relacionadas a compra de uva, e ocasionalmente na compra de vinhos, sendo, sobretudo, marcadas pela confiança, parceria, fidelidade e conhecimento das partes, o que tende a inibir comportamentos inoportunos.

Como limitação deste trabalho destaca-se a impossibilidade de entrevistar todos os produtores de uva na amostra de municípios selecionada, o que poderia trazer diferentes perspectivas. O corte temporal do estudo também caracteriza a situação encontrada no momento das entrevistas, apesar de alguns aspectos ocorridos ao longo da trajetória das vinícolas terem sido considerados.

Como sugestão para futuros trabalhos destacase a possibilidade de analisar as relações entre os elos produtor e beneficiador de uva em outras regiões, visando verificar diferenças ou convergências nas formas em que as transações são realizadas. Outra sugestão seria estudar o panorama econômico atual da vitivinicultura na região Meio-Oeste catarinense, analisando a viabilidade da produção das vinícolas.

\section{REFERÊNCIAS}

ARGYRES, N.; ZENGER, T. Capabilities, Transaction Costs, and Firm Boundaries. Organization Science, Articles in Advance, p. 1-15, 2012.
BARZEL, Y. A theory of the state: economic rights, legal rights, and the scope of the state. Cambridge University Press, 2002.

BARZEL, Y. Standards and the form of agreement. Economic Inquiry, v.42, n.1, p.1-13, 2004.

BARZEL, Y. Organizational Forms and Measurement Costs. Journal of Institutional and Theoretical Economics, v.161, p. 367-373, 2005

CALEMAN, S. M. Q.; ZYLBERSZTAJN, D.; PEREIRA, M. W. G.; OLIVEIRA, G. M. Organizational tolerance in agro-industrial systems: an empirical application for the meat sector. RAUSP Management Journal, v. 52, p. 456-466, 2017

CALIARI, V. Uva e Vinho. In: Síntese Anual da Agricultura de Santa Catarina, 2013-2014. Florianópolis: Epagri/Cepa. 2014.

COASE, R.H. The Nature of the Firm. Economica, v.4, November, 1937.

CROOK, T. R.; COMBS, J. G.; KETCHEN JR, D. J.; AGUINIS, H. Organizing around Transaction Costs: What have we learned and where do we go from here? Academy of Management Perspectives, Vol. 27, n. 1, p. 63-79, 2013.

EPAGRI. Empresa de Pesquisa Agropecuária e Extensão Rural de Santa Catarina. Fruticultura Catarinense em números - 2012/13 (Versão preliminar). Epagri/Cepa. Florianópolis, 2013.

IBGE. Instituto Brasileiro de Geografia e Estatística. Sistema IBGE de Recuperação Automática de Dados. 2015.

MARCONI, M.A.; LAKATOS, E.M. Técnicas de pesquisa: planejamento e execução de pesquisas, amostragens e técnicas de pesquisas, elaboração, análise e interpretação de dados. $3^{\mathrm{a}}$ ed. São Paulo: Atlas, 1996.

MÉNARD, C. The economics of hybrid organizations. Journal of Institutional and Theoretical Economics, p. 345-376, 2004.

MÉNARD, C. Research frontiers of new institutional economics. RAUSP Management Journal, v. 53, Abril, 2018. 
MÉNARD, C.M.; SHIRLEI, M. M. The future of new institutional economics: from early intuitions to a new paradigm. Journal of Institutional Economics, v. 10, Special Issue 04, p. 541 - 565, December 2014.

NEVES, L. W. A.; HAMACHERA, S.; SCAVARDA, L. F. (2014). Outsourcing from the perspectives of TCE and RBV: A multiple case study. Production, v. 24, n. 3, p. 687-699, July/Sept, 2014.

NORTH, D.C. Custos de Transação, Instituições e Desempenho Econômico. Rio de Janeiro, 1998.

SANTOS, N. M.; FERRAZ, I. N. F.; FALQUETO, J. M. Z.; VERGA, E. A Teoria dos Custos de Transação nas Pesquisas de Estratégia no Brasil. Revista IberoAmericana de Estratégia, v. 16, n. 2, Abril/Junho, 2017
SIMIONI, J. Informações sobre as vinícolas da região. [Mensagem pessoal]. Mensagem recebida em várias datas. 2015.

WILLIAMSON, O.E. The Economic Institutions of Capitalism. New York, 1985.

WILLIAMSON, O. E. The mechanisms of governance. New York: Oxford University Press, 1996

WILliamsON, O.E. The theory of the Firm as Governance Structure: from choice to contract. 2002.

ZYLBERSZTAJN, D. Papel dos contratos na coordenação agro-industrial: um olhar além dos mercados. RER, Rio de Janeiro, v.43, n.3, p.385-420, jul./set. 2005 . 